The Sustainable City XII 573

\title{
CLIMATE CHANGES AND DRINKING WATER IN SUSTAINABLE CITIES: IMPACTS AND ADAPTATION
}

\author{
MANUEL RODRIGUEZ \& IANIS DELPLA \\ Centre de Recherche an Aménagement et Développement (CRAD), Université Laval, Québec, Canada
}

\begin{abstract}
Planning and management of sustainable cities must consider the impacts of climate changes on urban water resources. There is a growing concern about how climate changes affect the quality of drinking water from the catchment to the citizen's tap. Changes in precipitation and temperature patterns can have effects on quality of water sources and on the capacity of water treatment and distribution infrastructure to respond with such changes. We present herein a research program that investigates the potential impacts of climate change scenarios on source and drinking water quality. The research methodology is based on a modelling framework that exploit datasets from Canadian cities concerning land use, source and tap water quality, water infrastructure and operations, and estimations on future changes on water temperature and local rainfall. The paper concludes with the initiatives that municipalities must conduct in order to implement sustainable strategies for adapting to climate changes regarding drinking water resources.
\end{abstract}

Keywords: drinking water, cities, climate change, impacts, adaptation.

\section{INTRODUCTION}

Drinking water is one of the most important services provided by cities to population. Sustainable cities must ensure the distribution of safe drinking water at any time, despite the fact that source waters are more and more vulnerable to land use pressures and climate changes. The quality of source waters is particularly sensitive to anthropogenic pressures resulting from land use such as agriculture, urban sprawl, deforestation, area waterproofing, etc. Climatic variables such as temperature and precipitations could lead to a decrease in the quality of drinking water sources when contaminants are transported by overland and subsurface flow and discharged into surface waters following rainfall events [1]. As an example, increases in organic contaminants such as road salts and organic matter may occur [2], [3]. According to the literature, heavy rainfall is the climatic factor with the greatest and most reported impacts on drinking water quality and safety, such as for example waterborne disease outbreaks [4], [5]. Changes in raw water quality consecutive to rainfall events can also have negative impacts for water treatment plants that use surface waters, such as membrane fouling and blocking, increase in chemical product dosing (increased coagulant and disinfectant doses, $\mathrm{pH}$ adjustments, etc.) and decrease in filter run-time [3]. All of these modifications (i.e., increases in organic matter and chloride/bromide, decrease in treatment performance, etc.) have the potential to modify the chemical water quality of drinking water, in particular the presence of disinfection by-products (DBPs).

Temperature and precipitation are expected to vary in the future in Canada and elsewhere due to increases in greenhouse gas emissions [6], [7]. Shifts in climate patterns (i.e., rainfall increase) could then have consequences on source water quality due to the intensification of surface and groundwater runoff contamination events, leading to a decline in drinking water treatment efficiency and ultimately in drinking water quality. 
Considering these potential impacts of land use and climate changes on the quality of raw and drinking waters, we designed a research program that aim to improve the understanding of the variation of water quality under climatic and land use pressures, and to model the potential consequences of modifications in the patterns of these pressures in the future. The results of this research program will help municipal decision-makers to identify strategies to reduce the impacts of land use and climate changes on drinking water quality distributed to the population.

Our research program is made up of three different projects (in total five sub-projects). These projects are dedicated to study the influence of land use, climate (rainfalls) and climate change on water quality, from the source to the tap. These projects were all conducted in the Province of Quebec, Canada.

\section{EFFECTS OF CLIMATE AND LAND USE ON SOURCE WATER QUALITY}

In this project, the relative influence of a set of watershed characteristics (climate, land use, morphology and pedology) and climatic variables on two key water quality parameters: turbidity and fecal coliforms (FC) was examined [8]. Fecal coliforms are a commonly used indicator of pathogens in water and is also used to assess microbial [9], [10]. Turbidity is an indicator of the presence of suspended solids, organic matter and microorganisms, and is also used to assess water treatment efficiency and potential chlorination by-product formation [11]. Twenty-four catchments located in the southern part of the Province of Quebec were studied at various spatial scales ( $1 \mathrm{~km}, 5 \mathrm{~km}, 10 \mathrm{~km}$ and the entire catchment).

With the use of Spearman's correlation rank tests, we revealed that the entire catchment was a better predictor of water quality for both water quality parameters. Based on this information, linear mixed effect models for predicting turbidity and FC levels were developed. A set of land use and climate scenarios was considered and applied within the water quality models. Four land use scenarios (Scenario 1: no change; Scenario 2: constant rate of land use variation; Scenario 3: optimistic (decrease in agricultural land, reforestation, no urban sprawling); and Scenario 4: pessimistic (increase in agricultural land, deforestation, and urban sprawling) and three climate change scenarios (based on emissions scenarios B1, A1B and A2) were tested. The variations for the near future (2025) were calculated and compared to the reference period (2000).

Climate change impacts on water quality remained low annually for 2025 time horizon (turbidity: $+1.5 \%$, FC: $+1.6 \%$, for the high emissions scenario A2). On the other hand, the influence of land use changes appeared to predominate. Significant benefits for both parameters could be expected following the optimistic scenario (turbidity: $-16.4 \%$, FC: $-6.3 \%$; p $<0.05$ ) (Fig. 1(a)). However, pessimistic land use scenario led to significant increases on an annual basis (turbidity: $+11.6 \%, \mathrm{FC}:+15.2 \% ; \mathrm{p}<0.05$ ). Additional simulations conducted for the late 21 st century (2090) revealed that climate change impacts could become equivalent to those modeled for land use for this horizon (Fig. 1(b)).

Anticipation and quantification of surface source water contamination are vital in maintaining a high degree of safety for drinking water purposes. Best land use management practices such as the maintenance of riparian vegetation and wetlands, construction of retention ponds, application of fecal waste management plans and restriction of livestock in immediate catchment perimeters are particularly important to mitigate the risk of intensification of water quality degradation episodes associated with climate change [12]. Future modifications in agricultural practices itself due to advances in technologies or climate change (type of crops, fertilizers and pesticide uses, apparition of new cultivars, longer growing seasons) could also have important impacts on downstream surface waters. 

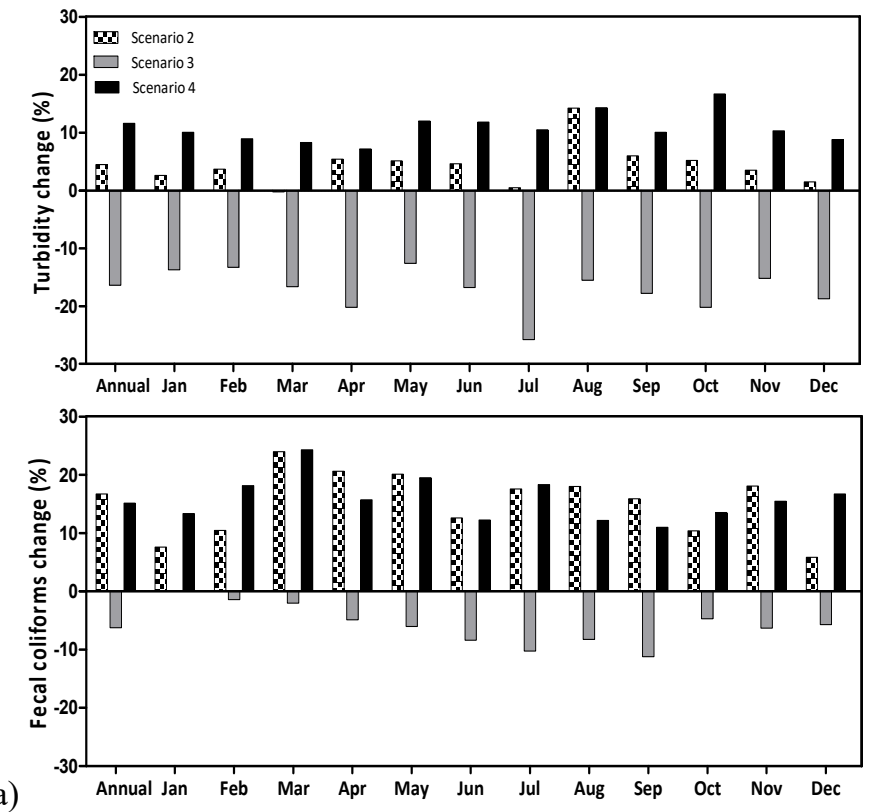

a)

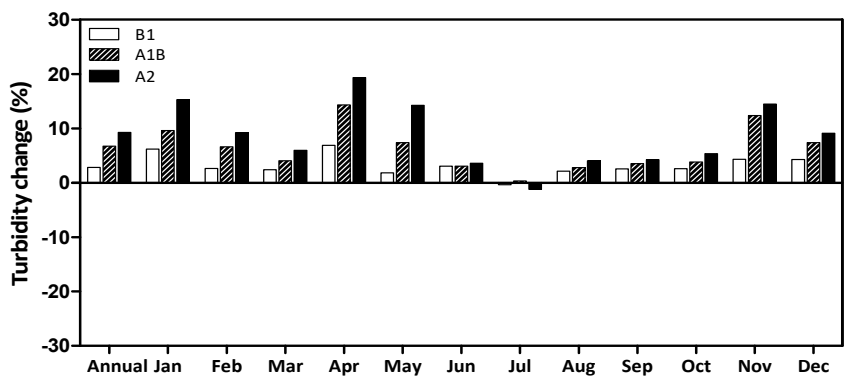

b)

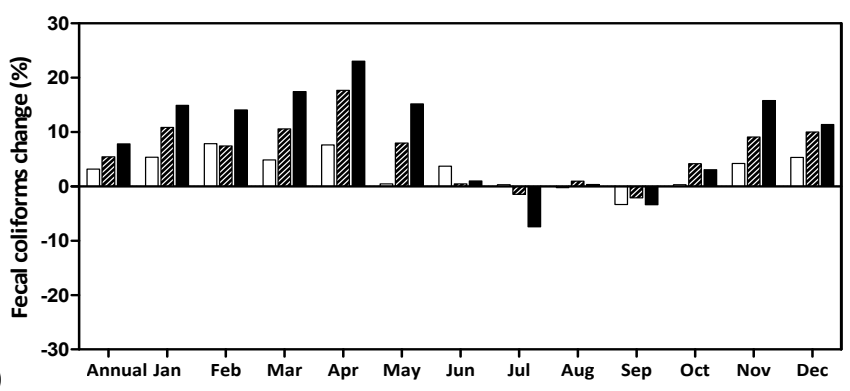

Figure 1: (a) Annual and monthly variations in turbidity and fecal coliform median concentrations between the three different land use scenarios (scenarios 2, 3 and 4) and reference (scenario 1) land use scenario in 2025 (under A1B scenario). (b) Annual and monthly variations in turbidity and fecal coliform median concentrations between climate change scenarios for late 21 st century (2090) and reference scenario (2000). 


\section{CONTAMINATION OF DRINKING WATER AND CLIMATE CHANGE SCENARIOS}

\subsection{Impacts of climate changes in water quality of small municipalities}

This study aims to assess the impacts of climate change (CC) scenarios on disinfection byproduct (DBP) formation in small water systems. To this end, a suite of models linking climate to DBPs was used [13]. This study applies three emissions scenarios (B1, A1B and A2) for three 30-year horizons $(2020,2050$ and 2080) in order to produce inputs to test several DBP models (trihalomethanes (THMs), haloacetic acids (HAAs) and haloacetonitriles (HAN)). This assessment was achieved for 13 small water systems located in Quebec, Canada and supplied by surface water. 17 DBPs models (10 for THMs, 6 for HAAs, and 1 for HAN) were selected and tested.

An annual increase is estimated for all DBPs for each CC scenario and horizon. The highest seasonal increases were estimated for winter for all DBP groups or species. In the worst-case scenario (A2-2080), THMs could be affected more particularly during winter $(+34.0 \%)$, followed by spring $(+16.1 \%)$ and fall $(+4.4 \%)$, whereas summer concentrations would remain stable $(-0.3$ to $+0.4 \%)$. Other DBPs groups (HAAs and HANs) shows smaller rises. Potentially, small water utilities applying only a disinfection step could be more affected by rising THM concentrations associated with CC than those having implemented a complete water treatment process (coagulation-flocculation, filtration and disinfection) with $+13.6 \%$ and $+8.2 \%$ increases respectively (A2-2080) (Fig. 2).

Further studies could include the modelling of other factors related to DBP formation (UV254, chlorine dose, $\mathrm{pH}$ or residence time) under climate modifications, especially bromide ion, a key DBP precursor whose levels could be modified by increasing rainfall. Developing predictive models for emerging DBPs such as nitrogenous DBPs (N-DBPs), halonitromethanes, haloacetamides and halonitromethanes is needed as these DBPs have been proven to be far more cytotoxic and genotoxic than THMs and HAAs [14]. In climate change studies, the results are dependent of the climate model chosen. Consequently, further studies should consider the inputs of various climate change models to better include and assess uncertainty in projections. Finally, more complete research could be achieved by combining our approach with the development of decision support systems to help drinking water managers anticipate the potential consequences of CCs on their drinking waters.
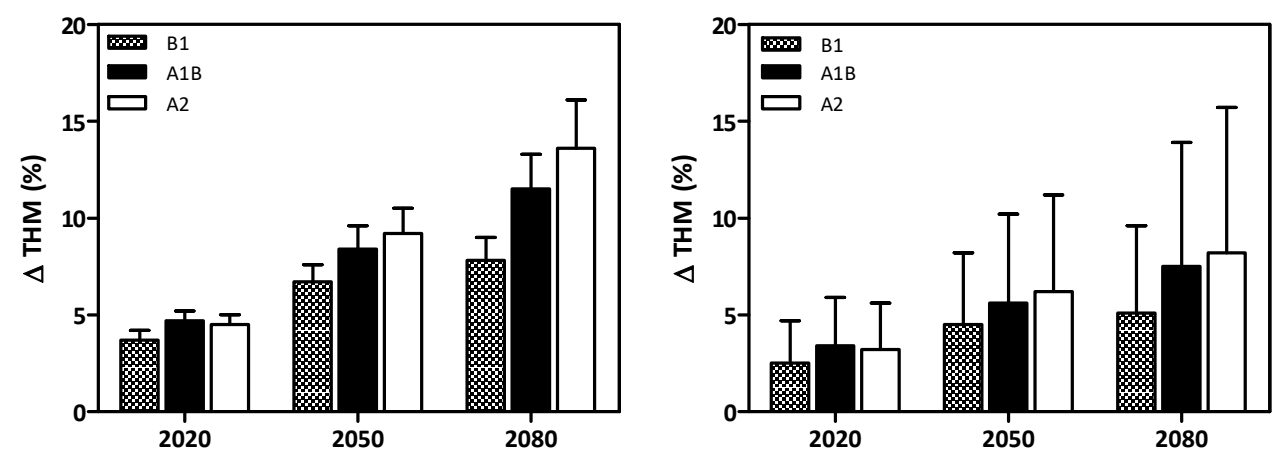

Figure 2: Comparison between mean annual THMs variations obtained with models using raw water data (left, 4 models tested) and those using treated waters data (right, 6 models tested). 


\subsection{Impacts of climate changes in chemical contamination peaks}

This project is strongly related with the precedent. The objective is to explore and estimate the impact of future possible variations in temperature and precipitation - associated with climate change scenarios - on the probability of THM4 (total trihalomethanes) concentrations exceeding a specific threshold $(80 \mu \mathrm{g} / \mathrm{L}$ (based on the mean annual regulatory threshold from the Quebec, Canada, drinking water regulation) [15].

A total of 112 drinking water utilities (DWUs) supplied by surface water and located in the Province of Quebec (Canada) were selected for this study. Possible variations in temperature and precipitation from the current period (2006-2009) to three predicted periods (2020: 2010-2039, 2050: 2040-2069, and 2080: 2070-2099) were estimated using two climate models: one global (CGCM3T47) and one regional (CRCM) and four emission scenarios (G.B1, G.A1B and G.A2 for the global climate model and R.A2 for the regional climate model). The probability of THM concentrations exceeding the threshold was calculated using a multilevel logistic regression model based on three variables (treatment type, temperature, and precipitation) and three hierarchical levels (THM samples, DWUs and the ecosystem at the source).

Results showed a relatively low, but statistically significant, increase in the probability of THM concentrations exceeding the threshold over time (between $1.9 \%$ and $4.7 \%$, depending on the emission scenario). Statistically significant differences in probability were found for the 2080 predicted period only, between the least extreme emission scenario (G. B1) and the most extremes emission scenarios (G.A2 and R.A2) and between the average emission scenario (G.A1B) and the most extreme emission scenario from the regional climate model (R.A2). Statistically significant differences in probability were found between the current period and both the 2050 and the 2080 predicted periods, for all emission scenarios. Finally, large statistically significant differences in probability were found between seasons (up to approximately 30\%) and between treatment types (between $25 \%$ and $40 \%$ ) with higher probabilities during summer, followed by fall, spring and winter, and for DWUs using chlorination alone as treatment (Table 1).

Extreme precipitation and drought may influence peaks in water quality by its impact on source water [16], [17]. In future work, it would be relevant to analyze the impact of extreme weather events on THMs (and other DBPs, including the emerging ones) concentrations or on their probability of exceeding regulatory or health-based thresholds.

\section{WATER CONTAMINATION FOLLOWING RAINFALL EVENTS}

\subsection{Full-scale study}

This project aims to investigate the effects of various spring rainfall events on the quality of treated waters at a large water treatment plant through the implementation of intensive water quality monitoring of raw, filtered and treated waters during different heavy rainfall events ( $>10 \mathrm{~mm}$ in 24h) [18]. The study was carried out in the region of Québec City, Canada, in a large water treatment plant (WTP) that provides water to 306000 inhabitants of the city. The Saint Charles river watershed is used as water source. Although the area is mainly covered by forest and urban land [19], the watershed is known to be polluted by road salt application leading to continuously increasing levels of chloride and conductivity [20].

Four spring rainfall events were monitored with the help of 24-bottles autosamplers (ISCO 6712FR) that were installed in the WTP at the raw water intake and after the filtration step, just before final chlorination. DBPs (four trihalomethanes and six haloacetic acids) and their 
Table 1: Comparison of the predicted probability (\%) of THM concentrations exceeding the threshold between the DWU treatment types according to time periods and seasons.

\begin{tabular}{llrrrrr|c}
\hline $\begin{array}{l}\text { Time } \\
\text { periods }\end{array}$ & $\begin{array}{l}\text { Treatment } \\
\text { type }\end{array}$ & Winter & Spring & Summer & Fall & Overall & $\begin{array}{l}\text { Intra- } \\
\text { annual } \\
\text { variation* }\end{array}$ \\
\hline Current & Cl2 & 28.8 & 35.4 & 69.8 & 59.4 & 48.6 & 41.0 \\
& Advanced & 4.0 & 6.3 & 30.2 & 20.2 & 15.1 & 26.2 \\
$\mathbf{2 0 2 0}$ & Cl2 & 29.6 & 35.9 & 70.6 & 60.1 & 49.3 & 41.0 \\
& Advanced & 4.2 & 6.5 & 31.2 & 20.8 & 15.6 & 27.0 \\
& & & & & & & \\
$\mathbf{2 0 5 0}$ & Cl2 & 31.8 & 37.6 & 72.6 & 61.8 & 51.2 & 40.8 \\
& Advanced & 4.8 & 7.3 & 33.4 & 22.4 & 16.9 & 28.6 \\
$\mathbf{2 0 8 0}$ & Cl2 & 33.9 & 39.2 & 74.4 & 63.8 & 53.1 & 40.5 \\
& Advanced & 5.5 & 8.2 & 35.7 & 24.4 & 18.3 & 30.2 \\
\hline \multirow{2}{*}{ Total } & Cl2 & 5.1 & 3.8 & 4.6 & 4.4 & 4.5 & \\
variation** & Advanced & 1.5 & 1.9 & 5.5 & 4.2 & 3.2 & \\
\hline
\end{tabular}

*Intra-annual variation presented in Table 1 correspond to the variation in probability between seasons having the lowest (i.e., winter) and the highest (i.e., summer) probabilities.

** Total variations correspond to the variation in probability between the current period and the 2080 predicted period. The overall total variation is significant for both treatment types ( $\mathrm{p}$-value $<0.01)$.

explanatory variables $(\mathrm{pH}$, turbidity, water temperature, specific ultraviolet absorbance, total and dissolved organic carbon, bromide and chlorine dose) were measured on samples collected.

The results showed that water quality degrades during and following rainfall, leading to small increases in THM4 and HAA6 in treated waters. While THM4 and HAA6 levels remained low during the prerainfall period $(<9 \mathrm{mg} / \mathrm{L})$ for the four sampling campaigns, small increases in THM4 and HAA6 during and after rainfall events were observed. During the rainfall and post-rainfall periods, concentration peaks corresponding to 3-fold and 2-fold increases (respectively $27.5 \mathrm{mg} / \mathrm{L}$ for THM4 and $12.6 \mathrm{mg} / \mathrm{L}$ for HAA6) compared to prerainfall levels were also measured (Fig. 3). A slight decrease in harmful brominated THM and HAA proportion was also observed following rainfall events.

Despite relatively low increases in the DBPs monitored, complementary studies should include measurements within the distribution system to assess the behaviour of regulated (and emerging) DBPs following rainfall. Emerging DBPs (e.g., halonitromethanes and haloacetonitriles) were also detected in this distribution system [21]. However, little is known about the behaviour of these DBPs and their precursors following rainfalls.

\subsection{Experimental study}

This study compares the influence of land use and climate on DBP precursors in two catchments supplying the region around the City of Québec, Canada, and assesses the variability of DBPs concentration and speciation following various experimental DBP formation tests [22]. 

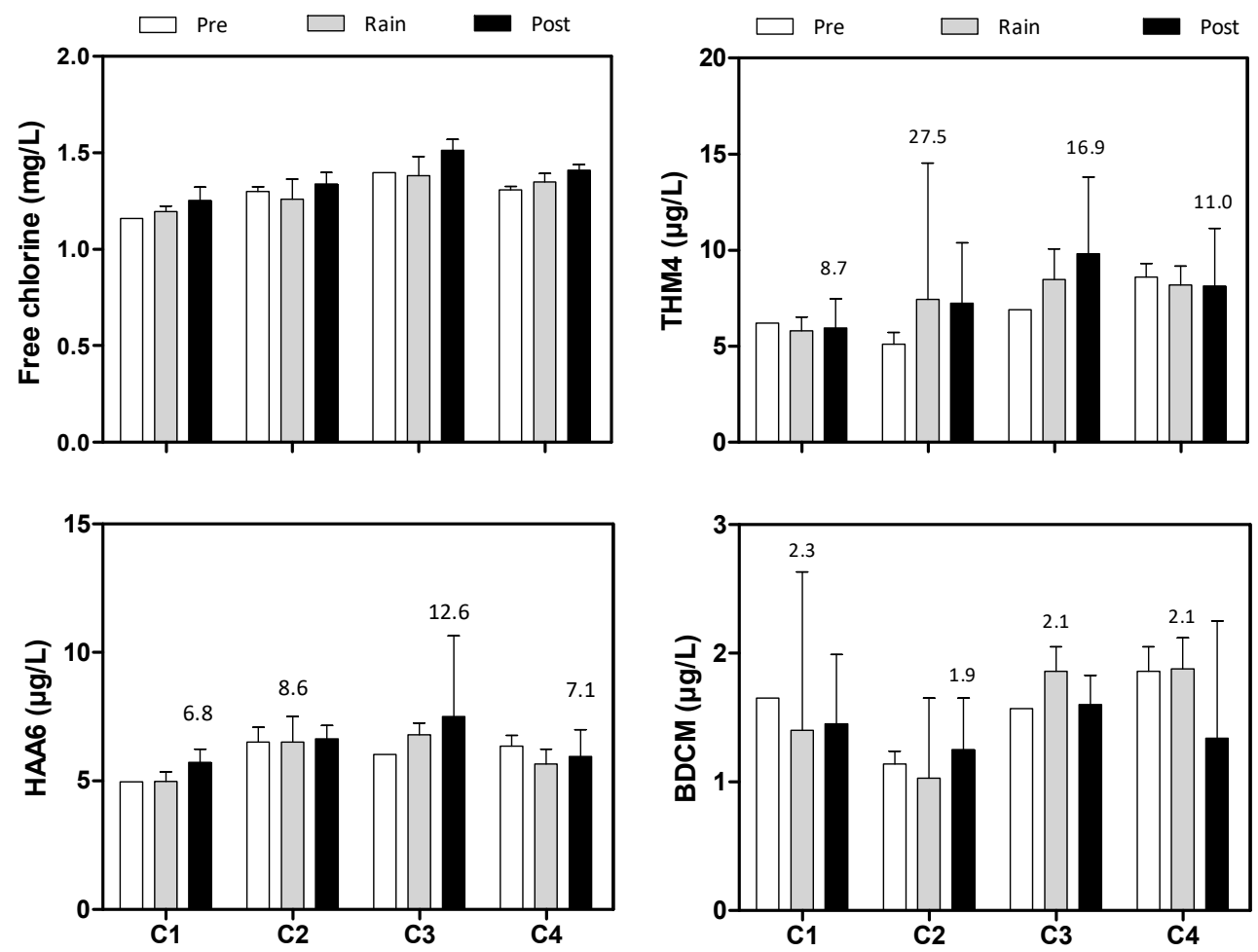

Figure 3: Free chlorine and DBP levels by hydroclimatic periods in treated waters. Means and standard deviation are indicated (4 sampling campaigns). Maximum DBP values by campaign are indicated.

The study was conducted in the Saint Charles and Chaudière rivers. Samples were collected using the same sampling protocol as in project 2.4. DBPs (THMs and HAAs) and their precursors in raw waters $(\mathrm{pH}$, turbidity, specific ultraviolet absorbance (SUVA), total and dissolved organic carbon, bromide and chlorine dose) were monitored. Various experimental chlorination tests: DBP formation potential (DBPFP) and Simulated Distribution Systems (SDS), were also performed.

Differences in pre-rainfall (baseflow) water quality were noted according to the different watershed land uses. Raw water quality patterns showed modifications between baseflow and rainfall periods, with a degradation of raw water quality according to turbidity and SUVA in both water sources. Rainfall events were also shown to alter organic matter reactivity with an increase in THM formation potential for both sites. A less noticeable impact on HAA formation potential was observed. However, no clear differences in DBPFP tests were observed between the sites (data not shown). SDS tests showed that rainfall events lead to considerable rises in organic carbon reactivity of filtered waters, even after primary treatment, with a 2-fold increase in THM and HAA concentrations following rainfall (Fig. 4) for waters representing the end of one main distribution system $(20 \mathrm{~h}$ contact time). These increases are linked mainly to a rise in non-brominated DBPs such as chloroform, trichloroacetic acid and dichloroacetic acid. 

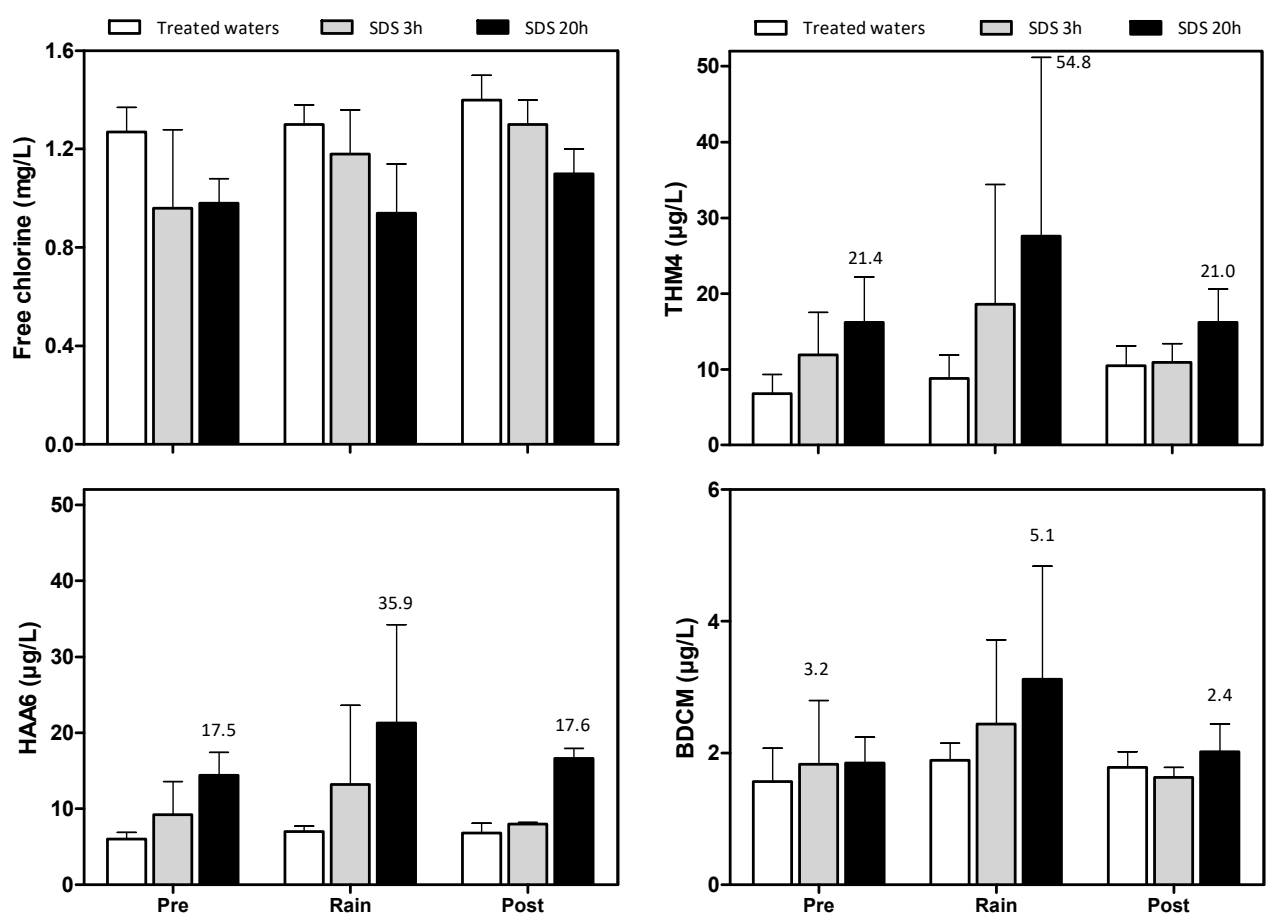

Figure 4: SDS tests (THM4 and HAA6) at $10^{\circ} \mathrm{C}$ for treated waters (contact time $=0 \mathrm{~h}$ ), and for $3 \mathrm{~h}$ and $20 \mathrm{~h}$ contact time. Means, standard deviation and maximum values for each hydroclimatic period are indicated (4 sampling campaigns).

This study confirms the importance of strictly controlling organic matter levels during drinking water treatment to ensure safe drinking water quality throughout the distribution system. The rechlorination of distributed waters is known to have a significant impact on THM and HAA concentrations [23]. It could be interesting to assess the effects of rechlorination on DBPs levels following rainfall events in distribution systems, since OM quality and quantity changes are observed even after a complete treatment and that these changes could affect DBPs formation experimentally.

\section{CONCLUSIONS}

Results of our research program suggest that sustainable cities need to generate reliable data on water quality from source to tap in order to assess the impact of climate changes on the presence of contaminants in raw and drinking waters. In addition, precise data on changes in land use must be developed, given the impact of anthropogenic pressures on source water quality. The use of different scenarios for precipitation and temperature changes associated with climate change on a regional level must be favoured for this type of study. The quality of data is the key factor in obtaining accurate estimates of the possible impacts of climate changes on drinking water quality. With solid data and reliable models, it will also be possible to identify adaptive measures aimed at reducing the impacts of climate change on water resources. City planners should consider such impacts in their decision-making in the design and the update of strategies for water source protection and urban water infrastructure 
management. This will allow them to better adapt to climate changes in the future. The adaptations aimed at reducing the impacts of climate change on drinking water must include: better policies for sustainable land-use management (urban, industrial, agricultural, etc.); source water protection plans that take into consideration future land use and climate parameter changes; the development of early warning systems to predict contamination peaks in raw water from treatment plants; improved treatment technologies to reduce the impacts of contamination peaks and emerging contaminants in source waters; renewal of distribution system pipes which account for potential changes in water demand and quality; and monitoring strategies for water quality and quantity from the watershed to the citizen's tap.

\section{REFERENCES}

[1] St-Hilaire, A., Duchesne, S. \& Rousseau, A.N., Floods and water quality in Canada: a review of the interactions with urbanization, agriculture and forestry. Can. Water Resour. J./Rev. Can. Des. Ressour. Hydr., 41(1, 2), pp. 273-287, 2016.

[2] Dailey, K.R., Welch, K.A. \& Lyons, W.B., Evaluating the influence of road salt on water quality of Ohio rivers over time. Appl. Geochem., 47, pp. 25-35, 2014.

[3] Ritson, J.P., Graham, N.J.D., Templeton, M.R., Clark, J.M., Gough, R. \& Freeman, C., The impact of climate change on the treatability of dissolved organic matter (DOM) in upland water supplies: a UK perspective. Sci. Total Environ., 473, pp. 714-730, 2014.

[4] Curriero, F.C., Patz, J.A., Rose, J.B. \& Lele, S., The association between extreme precipitation and waterborne disease outbreaks in the United States, 1948-1994. Am J Public Health, 91, pp. 1194-1199, 2001.

[5] Khan, S.J., Deere, D., Leusch, F.D., Humpage, A., Jenkins, M. \& Cunliffe, D., Extreme weather events: Should drinking water quality management systems adapt to changing risk profiles? Water Res., 85, pp. 124-136, 2015.

[6] DesJarlais, C., Allard, M., Bélanger, D., Blondlot, A., Bouffard, A., Bourque, A., et al., Adapting to climate change, Consortium Ouranos, Montréal, Québec, 2010.

[7] Mailhot, A., Beauregard, I., Talbot, G., Caya, D. \& Biner, S., Future changes in intense precipitation over Canada assessed from multi-model NARCCAP ensemble simulations. Int J Climatol, 32(8), pp. 1151-1163, 2012.

[8] Delpla, I. \& Rodriguez, M.J., Effects of future climate and land use scenarios on riverine source water quality. Science of the Total Environment, 493, pp. 1014-1024, 2014.

[9] Jokinen, C.C., Edge, T.A., Koning, W., Laing, C.R, Lapen, D.R., Miller, J. et al., Spatial and temporal drivers of zoonotic pathogen contamination of an agricultural watershed. J Environ Qual, 41(1), pp. 242-252, 2012.

[10] Lipp, E.K., Schmidt, N., Luther, M.E. \& Rose, J.B., Determining the effects of El Niño-Southern Oscillation events on coastal water quality. Estuaries, 24(4), pp. 491497, 2001.

[11] Dearmont, D., McCarl, B.A. \& Tolman, D.A., Costs of water treatment due to diminished water quality: a case study in Texas. Water Resour Res, 34(4), pp. 849853, 1998.

[12] St Laurent, J. \& Mazumder, A., The influence of land-use composition on fecal contamination of riverine source water in southern British Columbia. Water Resour Res, 48(12), W00M03, 2012.

[13] Scheili, A., Delpla, I., Sadiq, R. \& Rodriguez, M.J., Impact of raw water quality and climate factors on the variability of drinking water quality in small systems. Water Resources Management, 30(8), pp. 2703-2718, 2016. 
[14] Bond, T., Huang, J., Templeton, M.R. \& Graham, N., Occurrence and control of nitrogenous disinfection by-products in drinking water - a review. Water Res., 45(15), pp. 4341-4354, 2011.

[15] Delpla, I., Scheili, A., Guilherme S., Cool, G. \& Rodriguez, M.J., Variations of disinfection by-products levels in small drinking water utilities according to climate change scenarios: a first assessment. Journal of Water and Climate Change, 7(1), pp. $1-15,2016$.

[16] Chong Soh, Y., Roddick, F. \& van Leeuwen, J., The future of water in Australia: The potential effects of climate change and ozone depletion on Australian water quality, quantity and treatability. Environmentalist, 28, pp. 158-165, 2008.

[17] Hunter, P.R., Climate change and waterborne and vector-borne disease. Journal of Applied Microbiology, 94, pp. 37S-47S, 2003.

[18] Delpla, I. \& Rodriguez, M.J., Variability of disinfection by-products at a full-scale treatment plant following rainfall events. Chemosphere, 166, pp. 453-462, 2017.

[19] Jobin, B., Latendresse C., Maisonneuve, C. \& Grenier, M., Changements de l'occupation du sol dans le sud du Québec pour la période 1993-2001. Technical reports no 483. Sainte-Foy, Québec: Environnement Canada, Service Canadien de la Faune, Région du Québec, 2007.

[20] Association pour la protection de l'environnement du lac Saint-Charles et des Marais du Nord (APEL). Suivi du lac Clément - Évaluation de la contamination par les sels de voirie. Association pour la protection de l'environnement du lac Saint-Charles et des Marais du Nord, Québec, Canada, p. 46, 2010.

[21] Mercier-Shanks, C., Sérodes, J.B. \& Rodriguez, M.J., Spatio-temporal variability of non-regulated disinfection by-products within a drinking water distribution network. Water Res., 47, 3231-3243, 2013.

[22] Delpla, I. \& Rodriguez, M.J., Experimental disinfection by-product formation potential following rainfall events. Water Research, 104, pp. 340-348, 2016.

[23] Rodriguez, M.J., Sérodes, J.B. \& Levallois, P., Behavior of trihalomethanes and haloacetic acids in a drinking water distribution system. Water Res., 38, pp. 43674382, 2004. 